\title{
Policies and Professional Development: An Oil Boom's Effect on Rural
}

\author{
Schools and Teachers
}

\author{
Vincent Genareo \\ Iowa State University
}

In 2008, Western North Dakota experienced an extraordinary energy boom, creating waves of new residents seeking employment in the lucrative oil fields. Resultantly, many communities in the area, which were almost exclusively isolated and rural, dramatically changed. The purpose of this qualitative single-case study was to investigate the experiences of school staff in two rural schools within the North Dakota oil boom region. Data were teacher and administrator interviews with 15 participants and classroom observations. The findings indicated that teachers faced three key challenges in their classrooms as a result of the population influx, including: changing educational space, student academic proficiency, and a lack of cultural competence and pedagogical knowledge to effectively educate new, diverse students. Implications for policies and teacher professional development in rural boomtown areas are discussed.

Keywords: boomtown schools, teachers, rural policies

\section{Introduction}

Energy booms occur across the country (Lidji, 2012; Ragsdale, 2012), and can be polarizing to the community because of perceived risks and opportunities of the population growth that transform the local communities and customs (Schafft, Borlu, \& Glenna, 2013). In these areas, schools are also affected as personnel attempt to keep up with the changes. However, the rapid population growth and school and community impacts are not limited to energy industries; similar social and economic effects have been noted in rapid growth caused by tourism, technology industries, casino gaming, agriculture, manufacturing, and other job-producing industries (e.g. Leistritz \& Sell, 200; Wan, 2012). Nonetheless, teachers in rural boomtowns have been underrepresented in boomtown studies, which often focus on community disruptions, administrative policies, economics, and social outcomes. It is vital to understand needs of boomtown schools and teachers to inform policymakers in similar growth contexts how to prepare accordingly.

In 2008, economic conditions and technological advances led to the ideal setting for an oil boom in North Dakota. Communities that experience rapid growth as a result of job-creating industries are referred to as boomtowns because of the swift population surge (Olien \& Olien, 1982). The Bakken Shale Formation ("the Bakken"), a resource-rich sedimentary deposit, lies up to two miles under North Dakota, South Dakota, Montana, and Canada. It is estimated that there are nearly 7.4 billion barrels of recoverable oil, 6.7 trillion cubic feet of recoverable natural gas, and 500 million barrels of natural gas liquids (Demas, 2013, paras. 1 \& 7). Extracting oil from the Bakken created tens of thousands of jobs, many of which remained unfilled in North Dakota during the period of 2009-2014, and caused unpredictable growth in schools and communities (Mason, 2012). The region of North Dakota in which the Bakken is centralized is largely rural, isolated, and was not prepared for the sudden growth, which caused characteristic boomtown disruptions to regional infrastructure, housing, and economic resources (Farren, 2014).

Two communities existed in the booming area of North Dakota, and were in the early stages of growth during the time of this study. It is clear that rapid growth in rural schools will have some affect on policies and teachers. The limited research on boomtown schools has shown that schools that do not adequately prepare for and respond to rapid growth are unlikely to grow effectively, and all stakeholders in the school and community may be at personal, social, and economic risk (Ross \& Green, 1979). The purpose of this qualitative single-case study was to investigate the experiences of school staff in two rural schools within the North Dakota oil boom region.

\section{Related Literature}

During the 1970s and 1980s, researchers studied rapidly changing economies in rural areas resulting from energy resource extraction (Brookshire 
\& D’Arge, 1980). Much of the research was devoted to social effects of the community change. Findings suggested that rural infrastructure is inadequate for boomtown growth, resources prove insufficient, criminal activity increases, and social structures within the community can become strained (Freudenburg, 1986; Ruddell et al., 2014). The Social Disruption Theory is often used as a framework for understanding these boomtown disruptions (England \& Albrecht, 1984).

The Social Disruption Theory describes the effects of rapid growth on social structures (Kwan \& Mccartney, 2005) and communities (Smith, Krannich, \& Hunter, 2001). Social services (Weber, Geigle, \& Barkdull, 2014) and emergency services (Jacquet, 2005) can become burdened in boomtowns. Rural infrastructure, including roads, hospitals, water, sewage, and electrical systems, are often insufficient for the new residents (Petersen-Klein \& Borjon, 2011). There is nearly always a critical housing shortage because the supply of homes in rural areas is inadequate for the newcomer demands (Collins, Schecter, \& Carroll, 2008). In North Dakota, rent and home prices quadrupled almost overnight in some boomtown areas (Sulzburger, 2011). These community disruptions also affect schools situated in the rural towns. Often, boomtown schools experience crowding, student transience, and student diversity.

\section{Boomtown School Changes}

Crowding. Boomtown schools operate in the landscape of their changing communities. As the towns grow, the schools are faced with increased enrollment and financial needs (Raimi \& Newell, 2014). The classrooms, restroom facilities, and septic systems may not be adequate for the higher student enrollment (Brown, Hudspeth, \& Stone, 2000). Recruiting teachers in boomtowns is difficult due to inflated home prices and competing wages that can draw professionals away from their fields (Macke \& Gardner, 2012; Myler, 1982). Further complicating matters, schools in energy boomtown areas can grow so quickly and unpredictably that school leaders may be required to make decisions based on incomplete data or information (Genareo, 2013; Schafft, Glenna, Green, \& Borlu, 2014).

If schools do not receive the resources they need to address the changes, the additional students and resource demands may negatively impact the quality of education (Dalla et al., 2004, p. 239). School crowding can increase the likelihood of student absenteeism (Corcoran, Walker, \& White, 1988). Noise levels in crowded classrooms can have a further negative effect on student attention and learning (Mustafa et al., 2014). Teachers in crowded classrooms frequently spend more time planning and grading, resulting in increased anxiety (Fernandez \& Timpane, 1995).

Transience. Population transience is common in boomtowns, particularly as housing becomes more limited and costly (Schafft, Glenna, Borlu, \& Green, 2012). Students who move regularly to and from schools can challenge teachers who may receive little advanced notice of new students and, thus, cannot plan for necessary instructional adaptations (Lash \& Kirkpatrick, 1990). As communities grow, there is often an increase in special education needs that accompany the new, mobile families (Leistritz \& Sell, 2000). Transient students are more likely to have behavioral and academic difficulties, fail a grade (Herbers et al., 2012; Wood et al., 1993), and are less likely to graduate from school (Ross, 2014). And yet, hiring effective special education teachers in rural areas is notoriously difficult (Boe, 2014).

Diversity. Recent population shifts have made rural American schools more racially and ethnically diverse (Lichter, 2012). However, most American teachers are Caucasians and bring limited crosscultural backgrounds and knowledge into their teacher education programs (Sleeter, 2001). Much of their understanding of diversity in an educational context occurs in their post-secondary program, and the most beneficial experiences for pre-service teachers in their preparation for diversity typically are field placements in diverse settings (Wenger \& Dinsmore, 2005). Yet these experiences are limited in states with very low rates of diverse students, such as North Dakota (Beckman, 2012).

There are still many rural areas that are not ethnically, racially, or linguistically diverse. Teachers in these locations may need to extend their view of diversity to include all differences that contribute to identity and learning, including socioeconomic status, exceptionality, and gender (Eckert \& Petrone, 2013). Rural schools typically lack the political power, funding, and resources that their urban counterparts possess; as a result, many rural teachers still have little access to diversity-based professional development and know less about diversity-based instruction and learning (Burton, Brown, \& Johnson, 2013). In the case of boomtowns, though, newcomers may be more diverse than the traditional residents (Cornish, 2015). Still, little research exists that examines rural teachers' comfort with educating diverse students as schools undergo rapid population shifts.

Studies that focus on rural teachers during an oil boom are only starting to emerge, and thus far focus on policies around administrator decisionmaking in energy booms in Pennsylvania (Schafft, 
Glenna, Green, \& Borlu, 2014). Additionally, relatively little educational research has been done on rural boomtowns in the $21^{\text {st }}$ century, and with advances in technology and development, it is, in most ways, a "different kind of boomtown” (Malloy, 2010, p. 76) than those studied in the 1980s. Population booms will continue to occur throughout the country, and the issue of rural schools facing population growth deserves more attention. School administrators should understand boomtown classroom issues to better provide facilities and teachers the means to be successful during changing times.

This study will help fill the gaps in the literature by providing an understanding of educational conditions from the perspective of teachers and administrators in modern boomtowns and in the context of rural communities situated in a massive energy boom. The two research questions that guided this research were: (a) What changes occur in a rural, isolated district facing boomtown growth? and (b) How do the changes affect educational policies and practice?

\section{Methodology}

\section{Research Context}

A school district encompassing two communities and schools was included in this study. Major, ND, and Minor, ND (pseudonyms) are two small, isolated communities that were bound by a consolidated school district. Major, ND was a community of about 850 residents and located 50 miles from a small city of approximately 60,000 people. During the 2011-12 school year, Major School enrolled nearly 160 students in grades K-6, and about 170 students in grades 7-12, all in one building. There were 24 total teachers in Major School. Nearly all of the students in this school were Caucasian, with only a total of 9 of African American, Hispanic, or Native American ethnicity. At the start of the 2011-2012 school year, there were approximately 40 new students enrolled in Major School as a result of oil boom growth.

The other community, Minor, ND, was a town of fewer than 300 residents and was 70 miles from the nearest small city. Like Major, its population was growing, but not as quickly due to the lack of available housing and its more isolated location. Minor Elementary School was a small, K-6 school with about 40 students and six teachers. When students reached seventh grade, they were bussed 19 miles to Major School. At the start of the school year, there were 10 additional students in Minor Elementary School, which bucked the trend of a community and school that had declined in population every decade for the century prior.

\section{Qualitative Research Approach}

This study is a qualitative single-case study, which provides an understanding of a phenomenon in a real-world context and bound by space and time (Yin, 2011). The schools in the district were considered a single case since a consolidation bound them and they were both growing during the span of the academic year of this study. The fifteen participants included six elementary teachers, two special education teachers, five middle/secondary level teachers, and two administrators (12 teachers, two administrators). Semi-structured interviews with participants lasted from 45 to 60 minutes.

Participatory classroom observations of teachers occurred from November 2011 to November 2012, totaling about 400 hours. Administrators were not observed.

A general inductive approach was applied to analyze the transcripts (Thomas, 2006). Open coding was used to analyze the initial interview transcripts (Creswell, 2013). Some codes were developed a priori from the literature to compare if this case related to findings from previous studies (Leech \& Onwuegbuzie, 2007). Codes were then analyzed for similarity and representativeness of participant responses to develop themes, and eventually reached data saturation when no new codes or themes emerged (Maxwell, 2013). Three final themes developed which embodied classroom changes that might be assisted by policies, funding decisions, or professional development: Changing Educational Space, Student Academic Proficiency, and Diversity. To illustrate the coding process, the last theme, Diversity, contained codes such as: Religion, Cultural Differences, Professional Development Needs, Diversity Uncertainty, and Diversity Indifference. To help ensure credibility and trustworthiness, the researcher performed: extended fieldwork in the classrooms; triangulation of findings with literature, documents, interviews, and observation support; member checking of transcripts and findings for participant clarification; and peer debriefing with two experts familiar with this area of research (Creswell, 2013; Leech \& Onwuegbuzie, 2007).

\section{Findings}

Teachers in this school district experienced changes within their classroom and community space. The new students that accompanied the booming growth were generally transient. Most of these highly mobile students possessed lower 
academic proficiency, and teachers were unclear how to best help them. Additionally, no teachers in this case were confident in their knowledge of culturally responsive teaching and the role of diversity in educational theory or practice.

\section{Changing Educational Space}

The enrollment growth in the school district diminished the available classroom space and mandated the administration address issues of new hires, teacher housing, and student safety. About 50 new students joined the district throughout the 20112012 school year. The classes averaged about 27 students in the core junior high and high school subjects. In elementary, the kindergarten class was split into three sections. This posed a problem for a district that rarely split classes and did not have the room to do so.

Space was a greater issue for Major School, since it had a higher student enrollment and less available space prior to the growth. Some rooms were shared between several programs and teachers. The elementary music room shared space with the Head Start program and was also a storage area for classroom and kitchen supplies because, as one secondary teacher summarized, "We're already maxed out for space. We don't have anywhere else to go unless we build."

An elementary teacher felt the maximized space also diminished instructional opportunities, stating, "We don't have a lot of room. With all the materials and the leveled readers, and the centers that we'd like to do, we just can't do it.” As a response to the additional students and to partly address the demand for technical training in the oil fields, the school board opted for a permanent space solution and approved a multi-million dollar addition onto the school.

The new school addition included a new vocational agriculture department, science and business classrooms, and extra storage. The construction was a two-stage process; the first stage, or the initial frame build, was in progress in the fall semester of 2012 at a cost of over $\$ 1.3$ million. The second stage was awaiting company bids. The school was paying for it with a reduction of school reserves, fund money, and oil impact grants from the state. The superintendent reported the construction project was already $\$ 400,000$ over budget, and the school did not presently have the budget to complete it. The next and final stage of this project was estimated to cost the district almost $\$ 2$ million.

The special education room had recently moved into the old art room of the school, which was larger and could accommodate Major School's growing needs. The special education teacher reported, "New to our area, I probably gained 3 kids, but during the school year it seems like a lot for our program." According to the district elementary principal, the district planned to hire another paraprofessional in the coming year to assist with the new students' needs. The increasing student enrollment prompted the district to hire additional instructors, including two extra elementary teachers and a paraprofessional in 2011-2012, yet residential housing was an obstacle for hiring teachers.

It was challenging for the school district to hire new teachers for several reasons. First, there were shortages of teachers in 19 subject areas in North Dakota in the 2011-2012 school year (Baird, 2013). It was usually difficult to hire teachers in most rural North Dakota communities (Macke \& Gardner, 2012). The regional housing shortage and resulting high cost of living also made it difficult to pay rent or buy a home on a teacher's salary. The superintendent was forced to address this, stating, "We anticipated the growth, knew that there was not housing available. When housing is available, it's gonna be awfully expensive.” The school district purchased a quad-plex apartment building in 2011 for \$220,000, which, as of fall 2012, had four teachers living in it. The school board used money from its general fund to purchase it.

The base salary for starting teachers in the school district was $\$ 32,000$ a year. An elementary administrator realized that other boomtowns in the region were paying closer to $\$ 40,000$ a year, which caused some prospective teachers to ignore the district. As an incentive to new teachers, the school charged a nominal rent to teachers to live in the school's quadplex. The rent was deposited back into the school's general fund and the school custodians maintained the apartments. A secondary teacher explained, “I couldn't afford to buy a house on a teacher's salary here...that's pretty bad. But it's the biggest reason I could even work here, having somewhere to live.”

The space also proved to be a problem for safety and practicality. The Family, Career, and Community Leaders of America (FCCLA) teacher felt she could not safely have any more students in her room since her subject involved dangerous stovetops, knives, and cooking equipment. Most teachers felt that misbehavior was not an issue specific to new students. However, one secondary teacher was concerned that some of the new students were bringing in some other problems: "There are students that have come in...(and have) difference in attitude, and difference in work ethic is big.” The district also installed twelve security cameras in Major School and eight in Minor Elementary School 
during the year of this study. The superintendent explained, "We've had some incidences lately, vandalism in the locker room and whatnot. We just put them in to be safe." He felt it was "better to be safe than sorry, whether it was our kids or some of the new ones."

\section{Student Academic Proficiency}

As oil workers moved into the region, there was a high rate of student transiency. Some workers were migrant and would move with the jobs; others would find housing in rural towns temporarily, and move elsewhere when housing opened closer to their work sites. Teachers in this study felt unsure how to work with the mobile students. They were accustomed to teaching students who were born and raised in the community and had a fairly consistent educational program, and the newcomers often came and went suddenly and without warning.

The administrators and teachers agreed that academic levels of the new students were generally lower than the current students in the school. According to an administrator, the oil-related students' academic levels were “A to Z, with more probably, based on oil alone, probably more towards the Zs. Behaviorally, we haven't noticed that much.” Many school staff members attributed this to the high academic standards in North Dakota schools. Another administrator maintained, "We have a very strong educational perspective here, and a lot of the kids we see coming in are behind us." North Dakota student scores on the National Assessment of Educational Progress (NAEP) were statistically similar from 1992-2012, so as of this study, there was little evidence of a shift in standardized test results because of the new students (National Center for Educational Statistics, 2012).

Others believed the newcomers were academically deficient because of the transience itself; students were not given the consistency needed to develop their skills and knowledge. According to a secondary teacher, "A lot of them are transient and do come or go. The kids are out of sync, academically, with the rest of their peers.” Other teachers felt the new students' unstable home lives might have contributed to their academic levels. An elementary teacher explained, "Parents who work oil...drive a long way to work and aren't spending a lot of time with their kids.”

The lack of academic records may have also contributed to students' potential for academic success. When one elementary teacher got new students, she said it was "a guessing game at first. They have test data that follows them, but you don't know who you have until they're in front of you, and sometimes you still don't know for a while.” One of her students had moved from Georgia to Arizona to North Dakota within three months, and his school records were lost in the shuffle and lagged behind him when he arrived in Minor. Another student had virtually no records since he came from a state with few regulations on homeschooling, and this school was the first formal educational setting he attended.

Some teachers struggled to effectively teach (or feel effective teaching) new students with greater learning needs. An elementary teacher taught a struggling reader from another state and "didn't even know what to do with her." She and two other teachers tried more collaboration to generate ideas to get the student on track. They worked independently with her during their preparation hours and in class time, but did not believe she significantly improved during the student's time in the school, nor did they feel like they had the expertise or training to address her needs. An elementary teacher reported, "The school should provide some training for us. I'm not sure exactly what we need, but what we have isn't working with some of these little ones.”

\section{Diversity}

As students moved into this rural school district, they brought greater levels of student diversity. New students represented religions and cultures that were uncommon in these fairly homogenous communities. The English teacher explained:

We see more diversity, more special education...A third of my students are on IEPs...A lot of cultural diversity. They have different thoughts, experiences, things that are new. We've seen some students with different religions who don't go to the same churches as their friends, which can be a surprise here. It should be noted that it was not observed or reported in the interviews that teachers were addressing new students' cultural funds or knowledge or specifically engaging in strategies for new student acceptance.

No teachers in this study felt confident instructing students with other diverse backgrounds. A secondary teacher was not sure if diversities such as religion could even play a role in his pedagogy, explaining, "I don't really talk about church stuff, so things like the students' religion don't make a difference for me.” However, other teachers believed that more professional development in the area of diversity would be necessary in the future as the growth continued. One explained, "Diversity training is what we need now. Definitely as we grow more, 
but teachers here could use it now, with new types of students around here.”

None of the incoming students had language diversities. Although the teachers suggested they would not feel confident in their instructional efficacy when working with English Language Learners (ELL), an administrator noted, “We'll probably get some soon. We don't have anyone here certified, but we're part of a rural consortium (of area schools). If we ever need an ELL teacher, they'll provide one."

Teachers in this study were clear that they needed more space to teach, as theirs was running short due to student population growth.

Administrators made large financial decisions to simultaneously react to and prepare for increasing enrollment. The teachers felt unsuccessful in their educational approaches to educate the new, often transient students who brought academic issues and diversities with which they were unfamiliar. Many understood their professional deficits, but some teachers could not comprehend how diversity would matter to their classrooms at all. It was clear to most participants that the traditional approaches to teaching a homogeneous group of students might no longer work. The teachers desired more time for collaboration and specific professional development related to educating more transient and diverse students.

\section{Discussion}

School changes must be expected as a community transforms, and this was clear in the case of this oil boom study. The school district was simply a microcosm of the dramatic changes occurring in the communities around them. Crowding is one of the most evident and disruptive impacts of boomtown growth in communities, which is mirrored in the schools (Collins, Schechter, \& Carroll, 2008). This was true in this district, particularly in the more rapidly growing community of Major and its school. Adequate funding for facilities and updates can help alleviate strains to instructional space.

State funding policies must be addressed in boomtown schools. Most often in North Dakota, schools and regions impacted by oil boom had to apply for energy impact grants from the state to help fund their needs, or essentially ask for a portion back of revenue earned in their regions (Haggerty, 2012). Local regions in North Dakota received 20\% of the energy taxes, or $\$ 4.4$ billion, while the state took up to $\$ 2.8$ billion available in development aid to parcel out among the impacted communities (Macke \& Gardner, 2012). Boomtown schools simply need more immediate and assured state funding to help support successful growth and allow them to be proactive, and not reactive, to rapid growth.

Another funding revision resides in North Dakota's per-student funding formula. Although it is above the national average in total taxable resources, North Dakota is one of the top states requiring critical policy reform in its rural schools, partly due to its low teacher salary to instructional expenditures per pupil (Strange, Johnson, Showalter, \& Klein, 2012). Like many states, its per-student funding formula is based on the previous year's school enrollment (Beckman, 2012). Essentially, rapidly growing schools could be educating their new students with little, if any, allocated funding to do so. While North Dakota was one of the few states increasing funding in schools (Oliff \& Leechman, 2011), it would greatly benefit this state, and others, to modify funding formulas for schools with unpredictable populations to allow a larger portion of local revenue to subsidize any gaps in per-student funding. Booming industries and population growth should be an economic benefit for the schools, and not a cost (Kelsey et al., 2012).

Teachers in boomtowns might expect student transiency. The lower academic levels of the new students were difficult for teachers to address. Using good teaching practices, such as individualized instruction and collaboration, may be necessary for new, transient students' socialization and learning. However, it was not enough. Highly mobile students in other contexts tend to be academically behind their peers (Herbers et al., 2012). Teachers need more explicit professional development in understanding and empathizing transient students' obstacles (Gruman et al., 2008). Highly mobile students may come to school with missing or incomplete records, and some schools address this as they do with their homeless student population. Schools can borrow strategies used with homeless students and conduct parent interviews to "gather information that could make an immediate impact on a child's academic progress" prior to academic placement (Cook, Heintzman, \& McVicker, 2004, p. 58). Transient students may also lack social networks and support at the school and at home (Coleman, 1988). Teachers may facilitate some social connection in their classrooms through collaborative learning and deliberately authentic instruction that centers content, discussion, and assessment on the personal experiences and beliefs of students.

Teachers in rural boomtowns might have questions about helping students they are unaccustomed to teaching. This is not to say that all teachers would, nor to imply that diversity does not exist in rural settings. In this case, though, "rural North Dakota schools are predominantly white, English-speaking children from modest but adequate 
homes” (Beckman, 2012, p. 18). This is reflected in the teaching workforce in the state; $99 \%$ of teachers in North Dakota are Caucasian (Boser, 2011). The teachers in this case seemed caring, professional, and effective, but most had little experience with cultural, racial, or religious diversity that existed outside of their own community norms.

While these teachers may have lacked knowledge, Gay (2013) posits that some teachers, when faced with the opportunity to practice culturally responsive teaching, "resist by claiming incompetence (i.e., 'I would do if I knew how')" (p. 56). She suggests that teachers choose culturally relevant curricular materials (that address multiple perspectives and points of view), be willing to discuss student differences and issues of inequality, and to create bridges between theoretical aspects of diversity and students' lived experiences.

Additionally, an educational shift must be made away from "problems and weaknesses" of diverse students to "strengths, possibilities, and promises" (p. 68). There should be an understanding that new students bring unique funds of knowledge and learning opportunities.

All teachers, including those in rural settings, need multicultural competence to help inform their pedagogical practice. Maasum, Maarof, and Ali (2014) found that teachers responded positively to workshops that focused on self-awareness, awareness of other cultures, and pedagogy and resources. Social justice education addresses inequalities, facilitates cultural inclusion, and helps historically underserved populations thrive in academic settings; it should begin with administration leading a culture-change in their schools (DeMatthews \& Mawhinney, 2014). In the case of this rural district, diversity training was not offered, even as more teachers were becoming aware that it was needed. Administrators should consider providing these types of professional development opportunities to all teachers, not just those in a changing context, and enthusiastically articulate its potential to teachers.

It should be noted that in this boomtown case, similar to other recent findings (Brasier et al., 2014), the high school students were not dropping out of school in large numbers to work in the oil fields like they had in past energy booms (Ross \& Green, 1979), but many were drawn to the high-paying oil industry jobs after graduation. Their teachers were not alarmed by the changing attitudes of students who planned on working in the oilfields, since it was analogous to the laborious agricultural jobs many students worked before and after graduation. In fact, the school district seemed to embrace the oilfield jobs by updating their technical education shop to provide more opportunities for those who were interested in technical careers like oilfield work and agriculture. In this sense, the agricultural economy in which this oil boom was situated potentially alleviated some of the growing pains experienced by these schools.

\section{Conclusion}

Teachers in this study were faced with atypical challenges for their rural communities, and likely dealt with them as best they could. Nonetheless, it was clear that more support could have been offered to teachers at the district and state levels. The focus on this study was on the challenges schools were facing; however, the changes were not entirely negative. Population growth and multicultural students can be a great benefit to schools. The growth was also a welcome symbol of hope in these rural communities and schools that had lost population every decade since 1900. Further research should focus on the students (both new and traditional) in oil booms, to clarify student learning needs, home situations, social acceptance perceptions, and successes and challenges they face. Any observations of them in this study would have been merely anecdotal. More research should be done on understanding successful teachers' instructional adaptations in rapidly growing rural communities, particularly in the context of their schools and the needs of their students. Finally, quantitative research on school staff may give a wider perspective on the findings of this study.

Since this study only represented one case, it is not appropriate to generalize to all boomtown cases, including other districts in similar situations.

However, the limited literature that supports some of the findings indicates these issues might be common in boomtowns. Oil booms can have an overwhelmingly positive economic and social effect on rural communities and certain individuals. However, teachers in these communities need the backing of the state for funding and appropriate policy decisions that favor the rural teachers, students, and communities on the front lines of the oil boom, and from the district for professional development opportunities and supportive leadership. 


\section{References}

Beckman, J. (2012). Energy impact solutions models project. Department of Energy Award. Dickinson, ND.

Boe, E. E. (2014). Teacher demand, supply, and shortage in special education. Handbook of Research on Special Education Teacher Preparation, 67.

Boser, U. (2011). Teacher diversity matters: A stateby-state analysis of teachers of color. Washington, DC: Center For American Progress.

Brasier, K., Davis, L., Glenna, L., Kelsey, T., McLaughlin, D., Schafft, K., Biddle, C., Delessio-Parson, A., \& Rhubart, D. (2014). The Marcellus Shale impacts study: Chronicling social and economic change in North Central and Southwest Pennsylvania. The Center for Rural Pennsylvania, 1-65.

Brookshire, D., \& D’Arge, R. (1980). “Adjustment issues of impacted communities or, are boomtowns bad?” Natural Resources Journal, 20, 523-546.

Brown, R., Hudspeth, C., \& Stone, K. (2000). Lower enrollments and higher taxes are the primary issues faced by schools prior to a closure. TVA Rural Studies, Contractor Paper, 00-09.

Burton, M., Brown, K., \& Johnson, A. (2013). Storylines about rural teachers in the United States: A narrative analysis of the literature. Journal of Research in Rural Education, 28(12), 1-18.

Coleman, J. S. (1988). Social capital in the creation of human capital. American Journal of Sociology, 94, S95-S120.

Collins, B., Schechter, J., \& Carroll, S. (2008). Sublette County, Wyoming: An assessment of current housing conditions. Collins Planning Associates.

Cook, D., Heintzman, L., \& McVicker, J. (2004). Three elementary schools' experiences with access of services, welcoming culture and thoughtful placement of students. In E. A. James \& M. Milenkiewicz (Eds.), Colorado Educators Study Homeless and Highly Mobile Students, pp. 53-62. Denver, CO: Center for Research Strategies.

Corcoran, T., Walker, L., \& White, J. (1988). Working in urban schools. Washington, DC: Institute for Educational Leadership.

Cornish, A. (2015). Oil boom brings diversity to states out west. National Public Radio (NPR), May 15, 2015, retrieved from: http://www.npr.org/2015/05/25/409531251/oilboom-brings-diversity-to-states-out-west
Creswell, J. W. (2013). Qualitative inquiry and research design: Choosing among five approaches (3rd ed.). Thousands Oaks, CA: SAGE Publications, Inc.

Dalla, R., Villarruel, F., Cramer, S., \& GonzalezKruger, G. (2004). Examining strengths and challenges of rapid rural immigration. Great Plains Research, 14, 231-251.

Demas, A. (2013). USGS releases new oil and gas assessment for Bakken and Three Forks Formation. Retrieved from: http://www.usgs.gov/blogs/features/usgs_top_st ory/usgs-releases-new-oil-and-gas-assessmentfor-bakken-and-three-forks-formations/

Eckert, L. S., \& Petrone, R. (2013). Raising issues of rurality in English teacher education. English Education, 46(1), 68-81.

England, J., \& Albrecht, S. (1984). Boomtowns and social disruption. Rural Sociology, 49(2), 230247.

Farren, M. D. (2014). Boomtowns and the nimbleness of the housing market: The impact of shale oil and gas drilling on local housing markets. Paper prepared for presentation at the Agricultural \& Applied Economics Association's 2014 AAEA Annual Meeting.

Freudenburg, W. (1986). Social impact assessment. Annual Review of Sociology, 12, 451-478.

Fernandez, R. R., \& Timpane, P. M. (1995). Bursting at the seams: Report of the citizens' commission on planning for enrollment growth. New York, NY: Office of the Chancellor, New York City Board of Education. Gay, G. (2013). Teaching to and through cultural diversity. Curriculum Inquiry, 43(1), 48-70.

Genareo, V. R. (2013). On the cusp: A school district and two communities respond to an oil preboom (unpublished doctoral dissertation). University of North Dakota, Grand Forks, ND.

Gruman, D. H., Harachi, T. W., Abbott, R. D., Catalano, R. F., \& Fleming, C. B. (2008). Longitudinal effects of student mobility on three dimensions of elementary school engagement. Child Development, 79(6), 18331852.

Haggerty, M. (2012). Benefitting from unconventional oil: State fiscal policy is unprepared for the heightened community impacts of unconventional oil plays. Stanford University: Headwaters Economics. Retrieved from: http://legis.nd.gov/assembly/622011/docs/pdf/edt053012appendixk.pdf 
Herbers, J. E., Cutuli, J. J., Supkoff, L. M., Heistad, D., Chan, C. K., Hinz, E., \& Masten, A. S. (2012). Early reading skills and academic achievement trajectories of students facing poverty, homelessness, and high residential mobility. Educational Researcher, 41(9), 366374.

Jacquet, J. (2005). Index crimes, arrests, and incidents in Sublette County 1995-2004: Trends and forecasts. Sublette County, Wyoming. Retrieved from: http://www.pinedaleonline.com/socioeconomic/ pdfs/SubletteCoCrimeReport2005.pdf

Kelsey, T. W., Hartman, W., Schafft, K. A., Borlu, Y., \& Costanzo, C. (2012). Marcellus Shale gas development and Pennsylvania school districts: What are the implications for school expenditures and tax revenues? Penn State Extension Marcellus Education Fact Sheet. University Park, PA: The Pennsylvania State University.

Kwan, A. V. C., \& Mccartney, G. (2005). Mapping resident perceptions of gaming impact. Journal of Travel Research, 44(2), 177-187.

Lash, A., \& Kirkpatrick, S. (1990). A classroom perspective on student mobility. The Elementary School Journal, 91(2), 177-191.

Leech, N., \& Onwuegbuzie, A. (2007). An array of qualitative data analysis tools: A call for data analysis triangulation. School Psychology Quarterly, 22(4), 557-584.

Lichter, D. T. (2012). Immigration and the new racial diversity in rural America. Rural Sociology, 77(1), 3-35.

Lidji, E. (2012). Primary completes Montana test wells. Petroleum News: Bakken, 1(1), 14.

Leistritz, L., \& Sell, R. (2000). Agricultural processing plants in North Dakota: Socioeconomic impacts. Agricultural Economics Report No. 437, Department of Agricultural Economics, North Dakota State University, Fargo, ND.

Maasum, T. N. R. T. M., Maarof, N., \& Ali, M. M. (2014). Addressing student diversity via culturally responsive pedagogy. ProcediaSocial and Behavioral Sciences, 134, 101-108.

Macke, D., \& Gardner, D. (2012). Policy education white paper - Western North Dakota energy project. Bush Foundation: Center for Rural Entrepreneurship. Retrieved from: https://www.bushfoundation.org/sites/default/fil es/public/Foundation/Files/policyeducationwhit epaperwndep.pdf

Malloy, D. (2010). Who wins and who loses? A community approach to understanding the wellbeing of boomtown residents (unpublished doctoral dissertation). Utah State University, Logan, UT.

Mason, J. (2012). Oil production potential of the North Dakota Bakken. Oil \& Gas Journal. February, 10, 4.

Maxwell, J. (2013). Qualitative research design: An interactive approach (3rd ed.). Thousand Oaks, CA: SAGE Publications.

DeMatthews, D., \& Mawhinney, H. (2014). Social justice leadership and inclusion: Exploring challenges in an urban district struggling to address inequalities. Educational Administration Quarterly, 20(10), 1-38.

Mustafa, H. M., Mahmoud, S., Assaf, I. H., AlHamadi, A., \& Abdulhamid, Z. M. (2014). Comparative analogy of overcrowded effects in classrooms versus solving 'cocktail party problem' (Neural Networks Approach). International Journal of Science and Innovative Technology, 3(2), 175-182.

Myler, G. (1982). Mitigating boom town effects of energy development: A survey. Journal of Energy and Law Policy, 2(2), 211.

National Center for Education Statistics (2012). State Profiles. Retrieved from: http://nces.ed.gov/nationsreportcard/states/

Olien, R., \& Olien, D. (1982). Oil booms: Social change in five Texas towns. Lincoln, NE: University of Nebraska Press.

Oliff, P., \& Leachman, M. (2011). New school year brings steep cuts in state funding for schools. Center on Budget and Policy Priorities, 7. Retrieved from http://www.cbpp.org//sites/default/files/atoms/fi les/9-1-11sfp.pdf

Petersen-Klein, P., \& Borjon, J. (2011). Summary of North Dakota fact-finding mission. Kansas Corporation Commission. Retrieved from: http://www.kansascommerce.com/DocumentCe nter/Home/View/1057

Raimi, D., \& Newell, R. G. (2014). Shale public finance. Duke University Energy Initiative. Retrieved from: http://energy.duke.edu/sites/energy.duke.edu/fil es/files/Shale\%20Public\%20Finance\%20 Local\%20Revenues\%20and\%20Costs\%20Repo rt\%20Final.pdf.

Ragsdale, R. (2012). As Bakken oil booms, so does crime. Petroleum News: Bakken, 1(2), 17.

Ross, L. S. (2014). The influence of student mobility rate on the graduation rate in the state of New Jersey (unpublished doctoral dissertation). Seton Hall University, South Orange, NJ.

Ross, P., \& Green, B. (1979). Impacts of the rural turnaround on rural education. Austin, TX: National Educational Laboratory Publishers. 
Ruddell, R., Jayasundara, D. S., Mayzer, R., \& Heitkamp, T. (2014). Drilling down: An examination of the boom-crime relationship in resource-based boom counties. Western Criminology Review, 15(1).

Schafft, K. A., Borlu, Y., \& Glenna, L. (2013). The relationship between Marcellus Shale gas development in Pennsylvania and local perceptions of risk and opportunity. Rural Sociology, 78(2), 143-166.

Schafft, K. A., Glenna, L. L., Borlu, Y., \& Greene, B. (2012). Marcellus Shale Gas Development: What Does it Mean for Pennsylvania Schools? Marcellus Education Fact Sheet, Penn State Extension, The Pennsylvania State University.

Schafft, K. A., Glenna, L. L., Green, B., \& Borlu, Y. (2014). Local impacts of unconventional gas development within Pennsylvania’s Marcellus Shale Region: Gauging boomtown development through the perspectives of educational administrators. Society \& Natural Resources, 27(4), 389-404.

Sleeter, C. E. (2001). Preparing teachers for culturally diverse schools research and the overwhelming presence of whiteness. Journal of Teacher Education, 52(2), 94-106.

Smith, M., Krannich, R., \& Hunter, L. (2001).

Growth, decline, stability, and disruption: A longitudinal analysis of social well-being in four western rural communities. Rural Sociology, 66(3), 425-450.

Strange, M., Johnson, J., Showalter, D., \& Klein, R. (2012). Why rural matters 2011-12: The Condition of rural education in the 50 states. A report of the rural school and community trust policy program. Washington, DC: Rural School and Community Trust.
Sulzburger, A. (2011, November 25). North Dakota oil boom brings camps of men to the prairie. The New York Times, p. A12.

Thomas, D. R. (2006). A general inductive approach for analyzing qualitative evaluation data. American Journal of Evaluation, 27(2), 237246.

Wan, Y. K. P. (2012). The social, economic and environmental impacts of casino gaming in Macao: The community leader perspective. Journal of Sustainable Tourism, 20(5), 737755.

Weber, B. A., Geigle, J., \& Barkdull, C. (2014). Rural North Dakota's oil boom and its impact on social services. Social Work, 59(1), 62-72.

Wenger, K. J., \& Dinsmore, J. (2005). Preparing rural preservice teachers for diversity. Journal of Research in Rural Education, 20(10), 1-15.

Wood, D., Halfon, N., Scarlata, D., Newacheck, P., \& Nessim, S. (1993). Impact of family relocation on children's growth, development, school function, and behavior. Journal of the American Medical Association, 270(11), 13341338.

Yin, R. (2011). Applications of case study research ( $3^{\text {rd }}$ ed). Thousand Oaks, CA: SAGE Publications.

\section{About the author:}

Vincent Genareo is a postdoctoral research associate for the School of Education and the Research Institute for Studies in Education (RISE) at Iowa State University. His research areas include problem-based learning, teacher education pedagogy and policy, STEM career conceptualization and pathways to college, and rural boomtowns. 